\title{
ATRIBUT PRODUK INSTRIKSIK DAN EKSTRINSIK YANG DIPERTIMBANGKAN KONSUMEN DALAM MEMBELI PRODUK CAMILAN KHAS KOTA MALANG
}

\author{
Ahmad Karimur Rasyid \\ Universitas Brawijaya \\ karimurasyid@gmail.com
}

\begin{abstract}
ABSTRAK
Produk camilan khas merupakan produk yang menampilkan ke khasan suatu daerah selain harus tetap mempertahankan keunggulan bersaingnya sebagai suatu produk makan, dalam menciptakan keunggulan bersaing produknya produsen camilan khas malang perlu mengetahui atribut-atribut yang dipertimbangkan konsumen dalam memilih produk khas malang sehingga produk tersebut memiliki karakteristik yang dapat ditonjolkan dan menjadi sebuah keunggulan bersaing. Tujuan penelitian ini adalah untuk menjelaskan Atribut produk intrinsik (desain, merk, label, harga, polusi terhadap lingkungan, bersih, dan kemasan) yang di pertimbangkan konsumen dalam memilih produk camilan khas Kota Malang, atribut produk ekstrinsik (kandungan gizi, tekstur, kelezatan, rasa, aroma, warna, bentuk) yang di pertimbangkan konsumen dalam memilih produk camilan khas Kota Malang dan menjelaskan atribut produk yang paling dipertimbangkan konsumen dalam memilih produk camilan khas Kota Malang. Penelitian menggunakan metode penelitian explanatory survey. Di toko tempat penjualan camilan khas Malang di kota Malang. Sampel yang digunakan dalam penelitian ini sebanyak 140 orang responden dengan teknik pengambilan sampel menggunakan teknik Accidental Sampling. Penelitian ini menggunakan teknik analisis Confirmatory Faktor Analysis (CFA).Temuan penelitian ini ketujuh atribut produk intrinsik yang terdiri dari: kandungan gizi, tekstur, kelezatan, rasa, aroma, warna, dan bentuk serta ketujuh atribut produk ekstrinsik yang terdiri dari: desain, merk, label, harga, polusi terhadap lingkungan, bersih, dan kemasan merupakan atribut yang menjadi pertimbangan konsumen dalam memilih produk camilan khas Malang. Serta atribut sensori (rasa dan aroma) merupakan atribut yang paling di pertimbangkan konsumen dalam memilih produk camilan khas Malang.
\end{abstract}

Kata Kunci :

\section{PENDAHULUAN}

Keunggulan bersaing dalam perusahaan merupakan hal khusus yang dilakukan perusahaan yang memberinya kekuatan untuk menghadapi pesaing. Kompetensi ini bisa berwujud Merek yang menimbulkan persepsi kualitas tinggi atau dominasi atas saluran distribusi (Fandy, 1998:13).Salah satu upaya untuk menciptakan keunggulan bersaing adalah dengan mengembangkan produk.Menurut Porter (2007:73-74) salah satu strategy dalam keunggulan bersaing adalah mendifrensiasi produk atau jasa yang ditawarkan perusahaan yaitu menciptakan sesuatu yang baru yang dirasakan oleh industri secara menyeluruh sebagai hal yang unik. Menurut Kotler (2000:448)"Produk adalah elemen kunci dalam tawaran pasar (market offering). Perencanaan bauran pemasaran dimulai dengan memformulasikan tawaran untuk memenuhi kebutuhan atau keinginan pelanggan sasaran". Pengenalan atribut produk oleh perusahaan merupakan informasi yang penting bagi konsumen dalam melakukan pencarian informasi. Menurut Tjiptono (1998:103) Atribut produk adalah unsur-unsur yang dipandang penting oleh konsumen dan dijadikan dasar pengambilan keputusan pembelian.Menurut Sanzo et al (dalam Carmina Fandos dan Carlos Flavian 2006:649) terdapat 2 dimensi atribut produk yaitu atribut sentral atau attribut intrinsik adalah atribut-atribut spesifik untuk masing-masing produk yang akan menghilang ketika produk dikonsumsi dan tidak dapat diubah tanpa mengubah sifat dari produk itu sendiri. Atribut ekstrinsik adalah aspek yang berhubungan dengan produk tetapi tidak menjadi bagiannya secara fisik.Atribut produk intrinsik terdiri dari kandungan 
gizi, tekstur, kelezatan, rasa, aroma, warna, bentuk dan atribut produk ekstrinsik yang terdiri dari desain, Merek, label, harga, polusi terhadap lingkungan, bersih, dan kemasan. Proses pengambilan keputusan dapat dipandang sebagai tiga tahap yang berbeda namun berhubungan satu sama lain yaitu: tahap masukan (input), tahap proses dan tahap output. (Schiffan \& Kanuk 2007: 9). Terjadinya pertukaran informasi antara produsen dan konsumen terjadi dalam tahap proses, dalam tahap ini konsumen melakukan pencarian informasi tentang suatu produk. Informasi tentang pentingnya attribut produk dalam benak konsumen untuk pengembangan produk baru. Proses pengembangan produk yag dikendalikan oleh pasar akan berhasil bila menggabungkan kebutuhan konsumen dan prferensi konsumen. Hal tersebut merupakan kunci sukses dalam ilmu pemasaran, Crawford (dalam Zhang et.al; 2002:646). Dalam proses tersebut, model pilihan multi atribut dan keputusan seringkali digunakan untuk merancang produk pada bermacammacam industri. Dengan mengamati reaksi konsumen terhadap atribut-atribut produk, akan diperoleh estimasi sejumlah atribut yang berpengaruh terhadap evaluasi konsumen dan keputusan pembelian terhadap suatu produk. Estimasi tersebut dapat digunakan untuk membentuk model yang memprediksi kemungkinan respon konsumen terhadap rancangan produk baru.Perbedaan pandangan konsumen dalam mengidentifikasi atribut produk sangat penting dalam pengembangan suatu produk (Zhang et.al 2002:646). Dari permasalahan diatas peneliti tertarik untuk mengetahui atribut produk yang dipertimbangkan konsumen dalam membeli produk camilan khas Kota Malang.

\section{KAJIAN PUSTAKA DAN HIPOTESIS \\ Produk}

Produk adalah elemen kunci dalam tawaran pasar (market offering). Perencanaan bauran pemasaran dimulai dengan memformulasikan tawaran untuk memenuhi kebutuhan atau keinginan pelanggan sasaran. Pengertian produk tidak dapat dilepaskan dengan kebutuhan atau need, karena produk merupakan sesuatu yang dapat memenuhi kebutuhan manusia. Misalnya saja seseorang yang sedang lapar maka dia membutuhkan sesuatu yang dapat memenuhi kebutuhannya itu maka dia lalu mencari nasi. Apabila di situ tidak dapat ditemukan nasi maka dia akan mencari sesuatu yang lain yang dapat memenuhi kebutuhannya tersebut misalnya roti, atau jagung, ketela pohon, ataupun apa saja yang diharapkan dapat menghilangkan rasa laparnya itu. Segala sesuatu yang dapat memenuhi kebutuhan manusia itulah yang disebut produk. Menurut Gitosudarmo (2000:177) "produk adalah segala sesuatu yang diharapkan dapat memenuhi kebutuhan manusia ataupun organisasi".

\section{Komponen Atribut produk}

Menurut Sazo et al (dalam Carmina Fandos dan Carlos Flavian 2006:649) terdapat memaparkan macam-macam atribut produk diantaranya:

1. Atribut intrinsik seperti vitamin, mineral, tekstur, aroma, warna, tampilan dan sebagainya.

2. Attribut ekstrinsik seperti merek, label, informasi tentang penggunaan dan keuntungan, daftar kelengkapan, komitmen lingkungan, dan konotasi sosial dan budaya

\section{perilaku konsumen}

Pengertian perilaku konsumen sering disamakan dengan pengertian perilaku pembeli. Perilaku konsumen (consumer behavior) mengarah kepada perilaku orang yang akan menggunakan suatu produk melalui proses pertukaran. Sedangkan perilaku pembeli (buyer behavior) adalah perilaku orang yang membeli suatu produk melalui proses 
pertukaran.

\section{Jenis Perilaku Konsumen}

Menurut Assael dalam Kotler (2000:202) membedakan 4 jenis perilaku pembelian konsumen berdasarkan tingkat keterlibatan pembeli dan tingkat diferensiasi merek, yakni:

1. Perilaku pembelian yang rumit

2. Perilakupembelian pengurang ketidaknyamanan

3. Perilakupembelian karena kebiasaan

4. Perilaku pembelian yang mencari variasi

\section{Model perilaku konsumen}

Menurut (Sciffan \& Knuk 2000:553) model pengambilan keputusanadalah sebagai berikut:

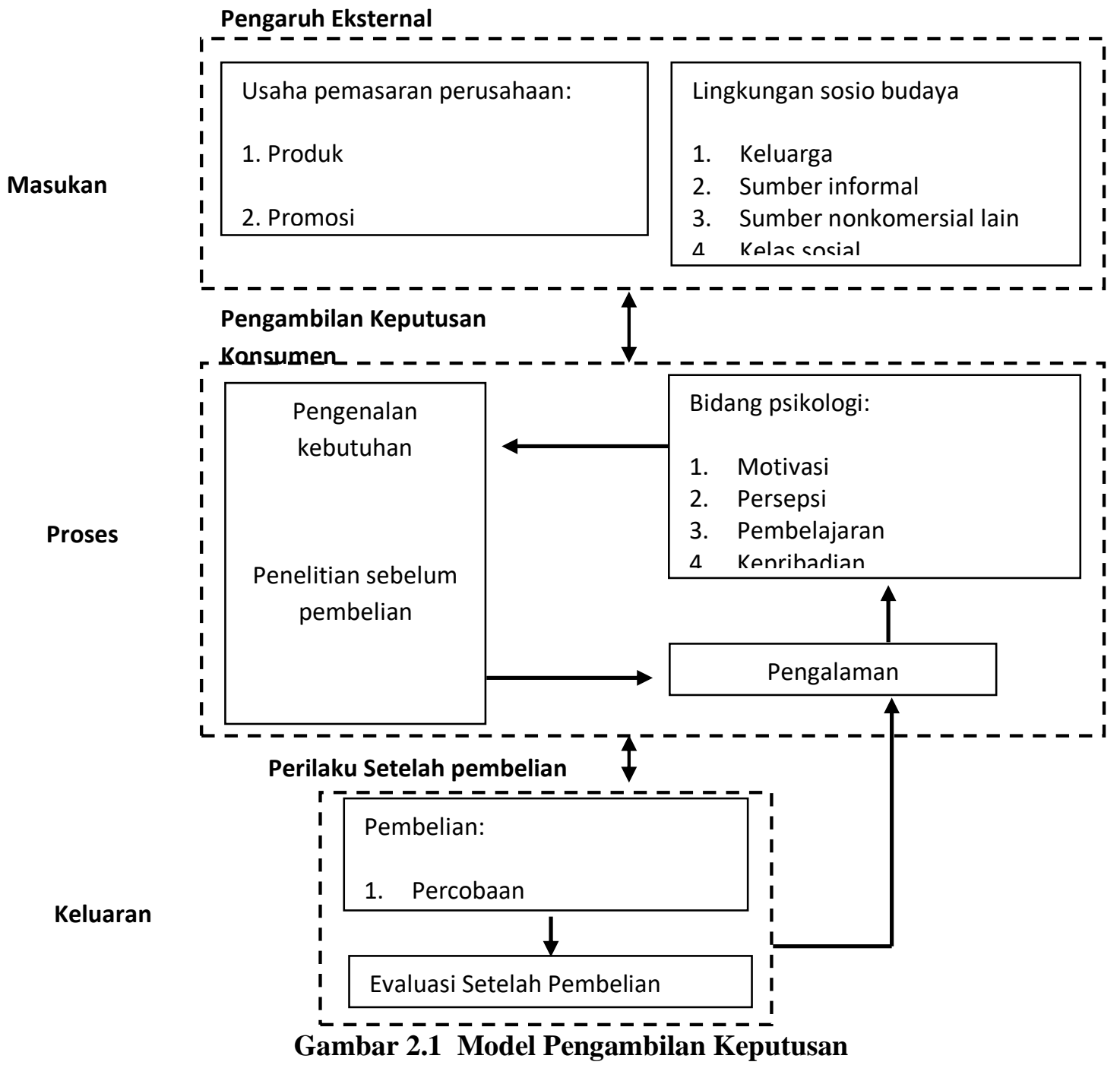

(Sumber: Sciffan \& Knuk 2000:554) 

a. Masukan
b. Proses
c. Keluaran

Sejalan dengan Sciffan \& Knuk, Swastha dan Irawan (2001:118-119) mengemukakan struktur keputusan pembelian konsumen meliputi:
a. Keputusan tentang Jenis Produk
b. Keputusan tentang Bentuk Produk
c. Keputusan tentang Merek
d. Keputusan tentang Penjualnya
e. Keputusan tentang Jumlah Produk
f. Keputusan tentang Waktu Pembelian
g. Keputusan tentang Cara Pembayarannya

\section{Kerangka Konseptual}

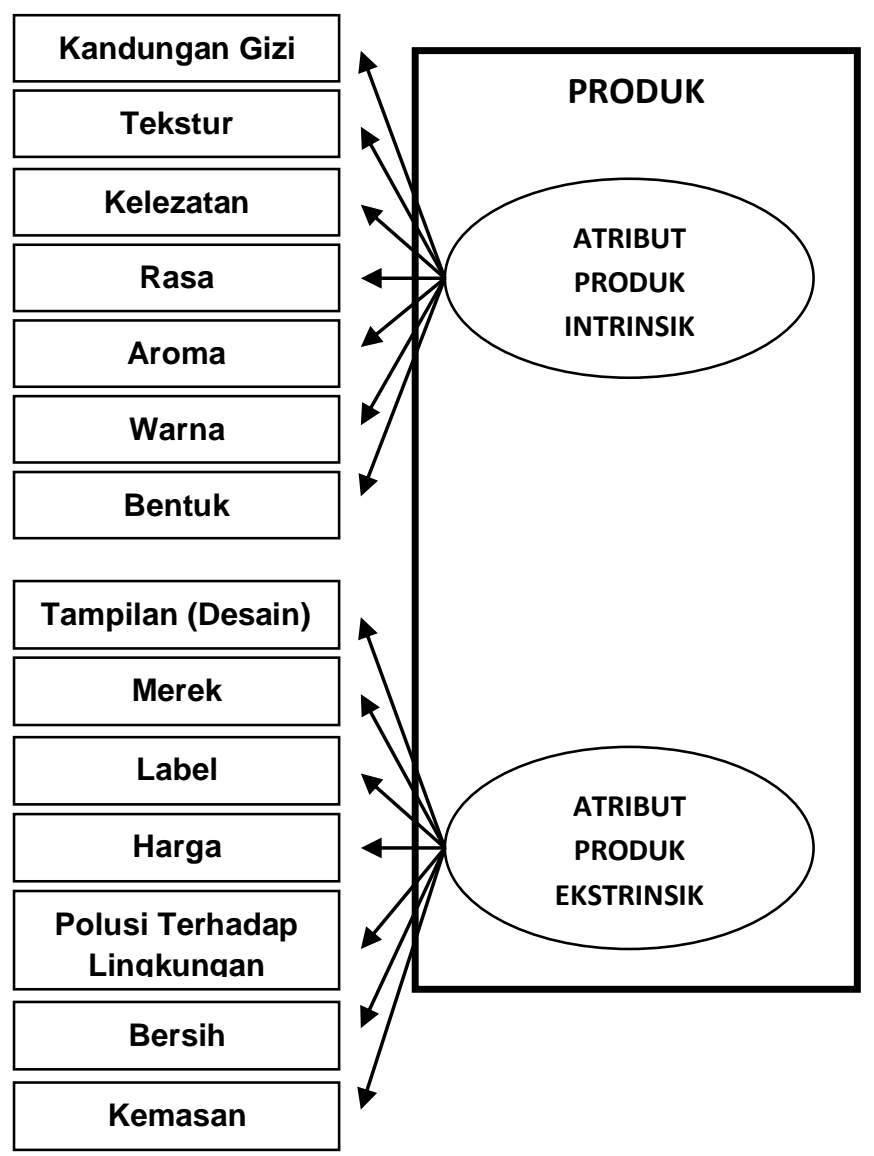

\section{Hipotesis Penelitian}

$\left(\mathrm{H}_{1}\right)$ Atribut produk intrinsik (kandungan gizi, tekstur, kelezatan, rasa, aroma, warna, bentuk) merupakan variabel yang dipertimbangkan konsumen dalam memilih produk. 
$\left(\mathrm{H}_{2}\right)$ Atribut produk ekstrinsik (desain, Merek, label, harga, polusi terhadap lingkungan, bersih, dan kemasan) merupakan variabel yang dipertimbangkan konsumen dalam memilih produk.

$\left(\mathrm{H}_{3}\right)$ Atribut sensori (aroma dan rasa) merupakan atribut produk yang paling dipertimbangkan konsumen dalam memilih produk camilan khas Malang.

\section{Definisi Operasional}

Attribut intrinsik adalah atribut-atribut spesifik untuk masing-masing produk yang akan menghilang ketika dikonsumsi dan tidak dapat diubah tanpa mengubah sifat produk itu sendiri. Dalam penelitian ini atribut-atribut produk intrinsik meliputi:

a) Kandungan gizi adalah persepsi konsumen tentang seberapa penting kandungan gizi dalam produk camilan khas Malang.

b) Tekstur adalah persepsi konsumen tentang seberapa penting tekstur yang berkaitan dengan halus, kasar, lembut atau renyahnya produk camilan khas Malang.

c) Rasa adalah persepsi konsumen tentang seberapa penting ke khasan beraneka macam rasa yang bisa menjadi pilihan konsumen dalam produk camilan khas Malang

d) Kelezatan adalah persepsi konsumen tentang seberapa penting kelezatan makanan yang bisa di nikmati konsumen produk camilan khas Malang

e) Aroma adalah persepsi konsumen tentang seberapa penting ke khasan aroma yang di hasilkan produk camilan khas Malang.

f) Warna adalah persepsi konsumen tentang seberapa penting warna makanan produk camilan khas Malang.

g) Bentuk adalah persepsi konsumen tentang seberapa penting ke khasan bentuk produk camilan khas Malang.

Atribut ekstrinsik adalah aspek yang berhubungan dengan produk tetapi tidak menjadi bagian produk secara fisik.

a) Desain adalah persepsi konsumen tentang seberapa penting tampilan produk secara keseluruhan menampilkan ke khasan produk camilan khas Malang.

b) Merek adalah persepsi konsumen tentang seberapa penting nama, istilah, tanda, symbol menampilkan produk khas kota Malang

c) Label adalah persepsi konsumen tentang seberapa penting kelengkapan informasi produk yang mencantumkan jenis rasa, komposisi, dan label dinas kesehatan.

d) Harga adalah persepsi konsumen tentang seberapa penting harga produk yang sesuai dengan selera konsumen.

e) Polusi terhadap lingkungan adalah persepsi konsumen tentang seberapa penting produk khas Malang ramah terhadap lingkungan atau tidak menimbulkan polusi terhadap lingkungan.

f) Bersih, adalah persepsi konsumen tentang seberapa penting kebersihan produk khas Malang.

g) Kemasan adalah persepsi konsumen tentang seberapa penting kemasan produk dapat melindungi produk secara keseluruhan.

\section{Metode Pengumpulan Data}

Penelitian ini menggunakan kuesioner dengan jenis kusioner tertutup menggunakan skala likert 5 point dengan alternatif pilihan sangat setuju, setuju, kurang setuju, tidak setuju, sangat tidak setuju.Skor 5 untuk pilihan "Sangat setuju", skor 4 untuk pilihan "Setuju", 
skor 3 untuk pilihan "Kurang setuju", skor 2 untuk pilihan "Tidak setuju", dan skor 1 untuk pilihan "Sangat tidak setuju". Selain kuesioner peneliti juga menggunakan wawancara dalam pengambilan data, data yang di ambil berupa data-data pendukung yang dapat memperkuat data penelitian. Teknik wawancara ini juga di gunakan untuk memperjelas kuesioner jika terdapat responden yang menginginkan penjelasan

1. Deskripsi Atribut Atribut Produk Intrinsik $\left(\mathrm{X}_{1}\right)$

Deskripsi atribut atribut produk intrinsik $\left(\mathrm{X}_{1}\right)$ terdiri dari 7 atribut yang di teliti diantaranya kandungan gizi, tekstur, kelezatan, rasa, aroma, warna dan bentuk yang diukur berdasarkan tingkat kepentingannya.

Tabel 5.4 Distribusi Frekuensi Atribut Produk Intrinsik (X1)

\begin{tabular}{|l|c|c|c|c|c|c|c|c|c|c|c|}
\hline \multirow{2}{*}{ Atribut } & \multicolumn{7}{|c|}{ Skor Jawaban } & \multirow{2}{*}{ Mean } \\
\cline { 2 - 13 } & \multicolumn{2}{|c|}{1} & \multicolumn{2}{|c|}{2} & \multicolumn{2}{c|}{3} & \multicolumn{2}{c|}{4} & \multicolumn{2}{c|}{5} & \\
\cline { 2 - 13 } & $f$ & $\%$ & $f$ & $\%$ & $f$ & $\%$ & $f$ & $\%$ & $f$ & $\%$ & Item \\
\hline Kandungan Gizi & 0 & 0.0 & 0 & 0.0 & 6 & 4.3 & 66 & 47.1 & 68 & 48.6 & 4.44 \\
\hline Tekstur & 0 & 0.0 & 6 & 4,3 & 22 & 15.7 & 72 & 51.4 & 40 & 28.6 & 4.04 \\
\hline Kelezatan & 0 & 0.0 & 5 & 3.6 & 13 & 9.3 & 61 & 43.6 & 61 & 43.6 & 4.27 \\
\hline Rasa & 0 & 0.0 & 1 & 0.7 & 14 & 10.00 & 57 & 40.7 & 68 & 48.6 & 4.37 \\
\hline Aroma & 0 & 0.0 & 2 & 1.4 & 12 & 8.6 & 53 & 37.9 & 73 & 52.1 & 4.40 \\
\hline Warna & 0 & 0.0 & 6 & 4.3 & 19 & 13.6 & 57 & 40.7 & 58 & 41.4 & 4.20 \\
\hline Bentuk & 0 & 0.0 & 7 & 5.0 & 28 & 20.0 & 69 & 49.3 & 36 & 25.7 & 4.09 \\
\hline
\end{tabular}

Sumber : Data primer diolah, 2009

Deskripsi Atribut Produk Ekstrinsik $\left(\mathrm{X}_{2}\right)$

Atribut Atribut Produk Ekstrinsik $\left(\mathrm{X}_{2}\right)$ terdiri dari 7 atribut yang di teliti diantaranya desain, merek, label, harga, polusi terhadap lingkungan, kebersihan, dan kemasan yang diukur berdasarkan tingkat kepentingannya.

Tabel 5.5 Distribusi Frekuensi Atribut Produk Ekstrinsik (X2)

\begin{tabular}{|c|c|c|c|c|c|c|c|c|c|c|c|}
\hline \multirow{3}{*}{ Atribut } & \multicolumn{10}{|c|}{ Skor Jawaban } & \multirow{2}{*}{ Mean } \\
\hline & \multicolumn{2}{|r|}{1} & \multicolumn{2}{|c|}{2} & \multicolumn{2}{|c|}{3} & \multicolumn{2}{|c|}{4} & \multicolumn{2}{|r|}{5} & \\
\hline & $\mathrm{F}$ & $\%$ & $\mathrm{~F}$ & $\%$ & $\mathrm{~F}$ & $\%$ & $\mathrm{~F}$ & $\%$ & $\mathrm{~F}$ & $\%$ & \\
\hline Desain & 0 & 0.0 & 3 & 2.1 & 18 & 12.9 & 51 & 36.4 & 68 & 48 & 4.31 \\
\hline Merek & 0 & 0.0 & 1 & 0.7 & 6 & 4.3 & 61 & 43.6 & 72 & 51.4 & 4.46 \\
\hline
\end{tabular}




\begin{tabular}{|l|c|c|c|c|c|c|c|c|c|c|c|}
\hline Label & 0 & 0.0 & 6 & 4.3 & 4 & 2.9 & 51 & 37.9 & 79 & 57.1 & 4.45 \\
\hline Harga & 0 & 0.0 & 7 & 5.0 & 21 & 15.0 & 68 & 48.6 & 44 & 31.4 & 4.06 \\
\hline $\begin{array}{l}\text { Polusi } \\
\text { Terhadap } \\
\text { Lingkungan }\end{array}$ & 0 & 0.0 & 6 & 4.3 & 5 & 3.6 & 50 & 35.7 & 79 & 56.4 & 4.44 \\
\hline Kebersihan & 0 & 0.0 & 3 & 2.1 & 16 & 11.4 & 71 & 50.7 & 50 & 35.7 & 4.20 \\
\hline Kemasan & 0 & 0.0 & 9 & 6.4 & 20 & 14.3 & 60 & 42.9 & 51 & 36.4 & 4.09 \\
\hline
\end{tabular}

Sumber : Data primer diolah, 2009

Analisis Uji Tingkat Validitas dan Reliabilitas Instrumen

Berdasarkan hasil hasil analisis terhadap tingkat validitas dan reliabilitas instrumen data pada 30 responden sebelum melakukan penelitian,

Tabel 5.6 Hasil Uji Validitas Item-Item Atribut Penelitian

\begin{tabular}{|c|c|c|c|c|}
\hline \multirow[b]{2}{*}{ ATRIBUT } & \multirow[b]{2}{*}{ Atribut/Indikator } & \multicolumn{2}{|c|}{ Validitas } & \multirow[b]{2}{*}{ Keterangan } \\
\hline & & $\begin{array}{l}\text { Korelasi } \\
\text { (R) }\end{array}$ & Sign.(p) & \\
\hline \multirow{7}{*}{$\begin{array}{c}\text { ATRIBUT } \\
\text { PRODUK } \\
\text { INTRINSIK (X1) }\end{array}$} & Kandungan Gizi & 0.735 & 0.000 & Valid \\
\hline & Tekstur & 0.468 & 0.009 & Valid \\
\hline & Kelezatan & 0.633 & 0.000 & Valid \\
\hline & Rasa & 0.559 & 0.001 & Valid \\
\hline & Aroma & 0.664 & 0.000 & Valid \\
\hline & Warna & 0.544 & 0.002 & Valid \\
\hline & Bentuk & 0.674 & 0.000 & Valid \\
\hline \multirow{7}{*}{$\begin{array}{c}\text { ATRIBUT } \\
\text { PRODUK } \\
\text { EKSTRINSIK } \\
(\mathrm{X} 2)\end{array}$} & Desain & 0.855 & 0.000 & Valid \\
\hline & Merek & 0.788 & 0.000 & Valid \\
\hline & Label & 0.794 & 0.000 & Valid \\
\hline & Harga & 0.466 & 0.009 & Valid \\
\hline & $\begin{array}{l}\text { Polusi Terhadap } \\
\text { Lingkungan }\end{array}$ & 0.616 & 0.000 & Valid \\
\hline & Kebersihan & 0.502 & 0.005 & Valid \\
\hline & Kemasan & 0.522 & 0.003 & Valid \\
\hline
\end{tabular}

Sumber : Data primer diolah, 2009 
Dari Tabel 5.12, diketahui bahwa hasil pengujian validitas item-item dengan indikator dari masing-masing atribut yang digunakan dalam penelitian ini adalah valid, seperti yang ditunjukkan dengan nilai Pearson Correlaton $\geq 0,300$ signifikan pada 0,000.

Tabel 5.7 Hasil Uji Reliabilitas Indikator-Indikator Atribut Penelitian

\begin{tabular}{|c|c|c|}
\hline Faktor & Cronbach's Alpha & Keterangan \\
\hline Atribut Produk Intrinsik (X1) & 0.693 & Reliabel \\
\hline Atribut Produk Ekstrinsik (X2) & 0.784 & Reliabel \\
\hline
\end{tabular}

Sumber : Data primer diolah, 2009

Berdasarkan Tabel di atas, diketahui bahwa semua instrumen adalah reliabel, seperti ditunjukkan dengan nilai cronbach's alpha lebih besar dari 0,6

Model Pengukuran (Measurement Model)

Dari hasil penelitian measurement model dengan cofirmatory faktor analysis menunjukkan bahwa seluruh atribut manivest/indikator adalah valid dan reliabel. Menurut Ghozali dan Fuad (2005:40) validitas indikator ditunjukkan oleh signifikansi pengruh atribut latent terhadap masing-masing indikatornya. Sedangkan reliabilitas ditentukan oleh koefisien diterminasi $\left(\mathrm{R}^{2}\right)$ pengaruh atribut latent terhadap indikator, composite reliability dan average extracted.

1. Validitas Instrumen

Tabel 5.8 Validitas Instrumen

\begin{tabular}{|c|c|c|c|c|c|}
\hline ATRIBUT & Atribut/Indikator & Nilai t-hitung & Nilai t-tabel & $\begin{array}{l}\text { Kriteria } \\
\text { Signifikansi } \\
\text { t- } \\
\text { hitung > t- } \\
\text { tabel }\end{array}$ & $\begin{array}{l}\text { Keterangan } \\
\text { validitas }\end{array}$ \\
\hline \multirow{7}{*}{$\begin{array}{l}\text { ATRIBUT } \\
\text { PRODUK } \\
\text { INTRINSIK } \\
(\mathrm{X} 1)\end{array}$} & Kandungan Gizi & 7.91 & 1.9771 & Signifikan & Valid \\
\hline & Tekstur & 8.32 & 1.9771 & Signifikan & Valid \\
\hline & Kelezatan & 8.93 & 1.9771 & Signifikan & Valid \\
\hline & Rasa & 14.37 & 1.9771 & Signifikan & Valid \\
\hline & Aroma & 9.00 & 1.9771 & Signifikan & Valid \\
\hline & Warna & 8.68 & 1.9771 & Signifikan & Valid \\
\hline & Bentuk & 8.32 & 1.9771 & Signifikan & Valid \\
\hline ATRIBUT & Atribut/Indikator & Nilai t-hitung & Nilai t-tabel & $\begin{array}{l}\text { Kriteria } \\
\text { Signifikansi } \\
\text { t-hitung > t- } \\
\text { tabel }\end{array}$ & $\begin{array}{l}\text { Keterangan } \\
\text { validitas }\end{array}$ \\
\hline \multirow{2}{*}{$\begin{array}{r}\text { ATRIB } \\
\text { UT PRODUK } \\
\text { EKSTRINSIK }\end{array}$} & Desain & 8.67 & 1.9771 & Signifikan & Valid \\
\hline & Merek & 8.11 & 1.9771 & Signifikan & Valid \\
\hline
\end{tabular}




\begin{tabular}{|c|c|c|c|l|r|}
\hline (X2) & Label & 12.57 & 1.9771 & Signifikan & Valid \\
\cline { 2 - 5 } & Harga & 12.62 & 1.9771 & Signifikan & Valid \\
\cline { 2 - 5 } & $\begin{array}{c}\text { Polusi Terhadap } \\
\text { Lingkungan }\end{array}$ & 9.92 & 1.9771 & Signifikan & Valid \\
\cline { 2 - 6 } & Kebersihan & 7.52 & 1.9771 & Signifikan & Valid \\
\cline { 2 - 6 } & Kemasan & 7.83 & 1.9771 & Signifikan & Valid \\
\hline
\end{tabular}

Sumber: Data primer diolah (2010)

Dari uji validitas diatas dapat disimpulkan bahwa semua atribut indikator adalah valid, dengan ditunjukkan oleh semua nilai t-hitung yang signifikan dengan $\alpha$ sebesar 5\%. Seperti disebutkan sebelumnya, validasi suatu indikator dapat di evaluasi dengan tingkat signifikansi pengaruh antara suatu atribut latent dengan indikatornya.

\section{Overal Goodness of Fit}

Menilai model fit adalah sesuatu yang kompleks dan memerlukan perhatian yang besar. Suatu indeks fit yang menunjukkan bahwa model adalah fit, tidak memberikan jaminan bahwa model memang benar-benar fit. Sebaliknya suatu indeks fit yang menyimpulkan bahwa model adalah sangat buruk tidak memberikan jaminan bahwa model tersebut benar-benar tidak fit (Ghazali dan Fuad, 2005). Dalam SEM peneliti tidak boleh hanya tergantung pada suatu indeks atau beberapa indeks fit, tetapi sebaiknya mempertimbangkan seluruh indeks fit.

Keseluruhan Goodness of Fit Statistic Atribut Produk Intrinsik (X1)

\begin{tabular}{|l|l|l|}
\hline Goodness of Fit Statistic & Nilai indeks X1 & Nilai indeks X2 \\
\hline Degress of Freedom & 14 & 14 \\
\hline Minimum Fit Function Chi-Square & $106.55(\mathrm{P}=0.0)$ & $105.59(\mathrm{P}=0.00)$ \\
\hline $\begin{array}{l}\text { Normal Theory Weighted Least Squares } \\
\text { Chi-Square }\end{array}$ & $0.0) \quad 85.29 \quad(\mathrm{P}=$ & \multicolumn{1}{|c|}{$115.30 \quad(\mathrm{P}=$} \\
\hline $\begin{array}{l}\text { Estimated Non-centrality Parameter } \\
\text { (NCP) }\end{array}$ & 71.29 & 101.30 \\
\hline \begin{tabular}{l} 
90 Percent Confidence Interval for NCP \\
\hline
\end{tabular} & $(45.85 ; 104.24)$ & $70.73 ; 139.35$ \\
\hline Minimum Fit Function Value & 0.77 & 0.76 \\
\hline $\begin{array}{l}\text { Population Discrepancy Function Value } \\
\text { (F0) }\end{array}$ & 0.51 & 0.73 \\
\hline 90 Percent Confidence Interval for F0 & $(0.33 ; 0.75)$ & $0.51 ; 1.00$ \\
\hline
\end{tabular}




\begin{tabular}{|c|c|c|}
\hline $\begin{array}{l}\text { Root Mean Square Error of } \\
\text { Approximation (RMSEA) }\end{array}$ & 0.19 & 0.23 \\
\hline $\begin{array}{l}90 \text { Percent Confidence Interval for } \\
\text { RMSEA }\end{array}$ & $(0.15 ; 0.23)$ & $0.19 ; 0.27$ \\
\hline $\begin{array}{l}\text { P-Value for Test of Close Fit (RMSEA } \\
<0.05)\end{array}$ & 0.00 & 0.00 \\
\hline Goodness of Fit Statistic & Nilai indeks X1 & Nilai indeks X2 \\
\hline $\begin{array}{l}\text { Expected Cross-Validation Index } \\
\text { (ECVI) }\end{array}$ & 0.82 & 1.03 \\
\hline $\begin{array}{l}90 \text { Percent Confidence Interval for } \\
\text { ECVI }\end{array}$ & $(0.63 ; 1.05)$ & $0.81 ; 1.30$ \\
\hline ECVI for Saturated Model & 0.40 & 0.40 \\
\hline ECVI for Independence Model & 3.91 & 4.15 \\
\hline $\begin{array}{l}\text { Chi-Square for Independence Model } \\
\text { with } 91 \text { Degrees of Freedom }\end{array}$ & 529.94 & 562.94 \\
\hline Independence AIC & 543.94 & 562.94 \\
\hline Model AIC & 113.29 & 143.30 \\
\hline Saturated AIC & 56.00 & 56.00 \\
\hline Independence CAIC & 571.53 & 604.53 \\
\hline Model CAIC & 168.48 & 198.48 \\
\hline Saturated CAIC & 166.37 & 166.37 \\
\hline Root Mean Square Residual (RMR) & 0.079 & 0.082 \\
\hline Standardized RMR & 0.079 & 0.082 \\
\hline Goodness of Fit Index (GFI) & 0.85 & 0.81 \\
\hline Adjusted Goodness of Fit Index (AGFI) & 0.70 & 0.62 \\
\hline $\begin{array}{l}\text { Parsimony Goodness of Fit Index } \\
\text { (PGFI) }\end{array}$ & 0.43 & 0.40 \\
\hline
\end{tabular}




\begin{tabular}{|l|l|l|}
\hline Normed Fit Index (NFI) & 0.80 & 0.81 \\
\hline Non-Normed Fit Index (NNFI) & 0.73 & 0.75 \\
\hline Parsimony Normed Fit Index (PNFI) & 0.53 & 0.54 \\
\hline Comparative Fit Index (CFI) & 0.82 & 0.83 \\
\hline Incremental Fit Index (IFI) & 0.82 & 0.83 \\
\hline Relative Fit Index (RFI) & 0.70 & 0.72 \\
\hline & \multicolumn{2}{|l}{} \\
\hline Critical N (CN) & 39.02 & 39.36 \\
\hline
\end{tabular}

Hasil Analisis Goodnees of Fit Indeks Atribut Produk Intrinsik (X1)

\begin{tabular}{|c|c|c|c|}
\hline $\begin{array}{l}\text { Goodness of Fit } \\
\text { Statistic }\end{array}$ & Kriteria Ketepatan Model & $\begin{array}{c}\text { Nilai } \\
\text { indeks X1 }\end{array}$ & Keterangan \\
\hline $\begin{array}{l}\text { Chi-Squire }\left(\mathrm{X}^{2}\right) \text { dan } \\
\text { Probabilitas } \mathrm{P}\end{array}$ & $\begin{array}{l}\text { Semakin kecil nilai } X^{2} \text { semakin } \\
\text { baik }(P \geq 0.05)\end{array}$ & $\begin{array}{l}106.55(\mathrm{P} \\
=0.0)\end{array}$ & Tidak Fit \\
\hline $\mathrm{NCP}$ & Semakin kecil semakin baik & 71.29 & Cukup Fit \\
\hline RMSEA & RMSEA $<0.10$ & 0.19 & Tidak Fit \\
\hline ECVI & $\begin{array}{l}\text { Lebih kecil dari ECVI for } \\
\text { independence dan mendekati } \\
\text { ECVI for saturated }\end{array}$ & 0.82 & Fit \\
\hline AIC & $\begin{array}{l}\text { Lebih kecil dari AIC for } \\
\text { independence dan mendekati } \\
\text { AIC for saturated }\end{array}$ & 113.29 & Fit \\
\hline RMR & $\mathrm{RMR} \leq 0.05$ adalah good fit & 0.079 & Tidak Fit \\
\hline GFI & $\begin{array}{l}\text { GFI } \geq 0.90 \text { adalah } \text { good fit, } 0.80 \\
\leq \text { GFI }<0.90 \text { madalah Marginal } \\
\text { fit }\end{array}$ & 0.85 & Marginal Fit \\
\hline AGFI & $\begin{array}{l}\text { AGFI } \geq 0.90 \text { adalah good fit, } \\
0.80 \leq \text { AGFI }<0.90 \text { madalah } \\
\text { Marginal fit }\end{array}$ & 0.70 & Tidak Fit \\
\hline PGFI & Lebih tinggi lebih baik $>0.6$ & 0.43 & Tidak Fit \\
\hline $\begin{array}{l}\text { Normed Fit Index } \\
\text { (NFI) }\end{array}$ & $\begin{array}{l}\text { NFI } \geq 0.90 \text { adalah } \text { good fit, } 0.80 \\
\leq \text { NFI }<0.90 \text { madalah Marginal } \\
\text { fit }\end{array}$ & 0.80 & Marginal Fit \\
\hline Parsimony Normed Fit & Lebih tinggi lebih baik & 0.53 & - \\
\hline
\end{tabular}




\begin{tabular}{|l|l|l|l|}
\hline Index (PNFI) & & & \\
\hline $\begin{array}{l}\text { Comparative Fit Index } \\
\text { (CFI) }\end{array}$ & $\begin{array}{l}\text { CFI } \geq 0.90 \text { adalah good fit, 0.80 } \\
\leq \text { CFI }<0.90 \text { madalah Marginal } \\
\text { fit }\end{array}$ & 0.82 & Marginal Fit \\
\hline $\begin{array}{l}\text { Incremental Fit Index } \\
\text { (IFI) }\end{array}$ & $\begin{array}{l}\text { IFI } \geq 0.90 \text { adalah good fit, 0.80 } \\
\leq \text { IFI }<0.90 \text { madalah Marginal } \\
\text { fit }\end{array}$ & 0.82 & Marginal Fit \\
\hline $\begin{array}{l}\text { Relative Fit Index } \\
\text { (RFI) }\end{array}$ & $\begin{array}{l}\text { RFI } \geq 0.90 \text { adalah good fit, 0.80 } \\
\leq \text { RFI }<0.90 \text { madalah Marginal } \\
\text { fit }\end{array}$ & 0.70 & Tidak Fit \\
\hline Critical N (CN) & & 39.02 & Kurang baik \\
\hline
\end{tabular}

Hasil Analisis Goodnees of Fit Indeks Atribut Produk Ekstrinsik (X2)

\begin{tabular}{|l|l|l|l|}
\hline $\begin{array}{l}\text { Goodness of Fit } \\
\text { Statistic }\end{array}$ & \multicolumn{1}{|c|}{ Kriteria Ketepatan Model } & $\begin{array}{l}\text { Nilai indeks } \\
\mathrm{X} 2\end{array}$ & Keterangan \\
\hline $\begin{array}{l}\text { Chi-Squire }\left(\mathrm{X}^{2}\right) \text { dan } \\
\text { Probabilitas P }\end{array}$ & $\begin{array}{l}\text { Semakin kecil nilai } \mathrm{X}^{2} \text { semakin } \\
\text { baik }(\mathrm{P} \geq 0.05)\end{array}$ & $\begin{array}{l}105.59(\mathrm{P}= \\
0.00)\end{array}$ & Tidak Fit \\
\hline NCP & Semakin kecil semakin baik & 101.30 & Cukup Fit \\
\hline RMSEA & RMSEA $<0.10$ & 0.23 & Tidak Fit \\
\hline ECVI & $\begin{array}{l}\text { Lebih kecil dari ECVI for } \\
\text { independence dan mendekati } \\
\text { ECVI for saturated }\end{array}$ & 1.03 & Fit \\
\hline AIC & $\begin{array}{l}\text { Lebih kecil dari AIC for } \\
\text { independence dan mendekati AIC } \\
\text { for saturated }\end{array}$ & 143.30 & Fit \\
\hline RMR & RMR $\leq 0.05$ adalah good fit & 0.082 & Tidak Fit \\
\hline GFI & $\begin{array}{l}\text { GFI } \geq 0.90 \text { adalah good fit, } 0.80 \leq \\
\text { GFI }<0.90 \text { madalah Marginal fit }\end{array}$ & 0.81 & Marginal Fit \\
\hline AGFI & $\begin{array}{l}\text { AGFI } \geq 0.90 \text { adalah good fit, 0.80 } \\
\leq \text { AGFI }<0.90 \text { madalah Marginal } \\
\text { fit }\end{array}$ & 0.62 & Tidak Fit \\
\hline PGFI & $\begin{array}{l}\text { Lebih tinggi lebih baik }>0.6 \\
\text { NFI } \geq 0.90 \text { adalah good fit, } 0.80 \leq \\
\text { NFI }<0.90 \text { madalah Marginal fit }\end{array}$ & 0.81 & 0.40 \\
\hline Lebih tinggi lebih baik & 0.54 & Tidak Fit \\
\hline
\end{tabular}




\begin{tabular}{|l|l|l|l|}
\hline Index (PNFI) & & & \\
\hline $\begin{array}{l}\text { Comparative Fit Index } \\
\text { (CFI) }\end{array}$ & $\begin{array}{l}\text { CFI } \geq 0.90 \text { adalah good fit, 0.80 } \leq \\
\text { CFI }<0.90 \text { madalah Marginal fit }\end{array}$ & 0.83 & Marginal Fit \\
\hline $\begin{array}{l}\text { Incremental Fit Index } \\
\text { (IFI) }\end{array}$ & $\begin{array}{l}\text { IFI } \geq 0.90 \text { adalah good fit, 0.80 } \leq \\
\text { IFI }<0.90 \text { madalah Marginal fit }\end{array}$ & 0.83 & Marginal Fit \\
\hline Relative Fit Index (RFI) & $\begin{array}{l}\text { RFI } \geq 0.90 \text { adalah good fit, } 0.80 \leq \\
\text { RFI }<0.90 \text { madalah Marginal fit }\end{array}$ & 0.72 & Tidak Fit \\
\hline Critical N (CN) & & 39.36 & Kurang baik \\
\hline
\end{tabular}

Hasil Pengujian Hipotesis

Nilai Loading Atribut Atribut Produk Intrinsik

\begin{tabular}{|l|c|c|c|}
\hline \multicolumn{1}{|c|}{ Atribut } & Nilai Loading & \multicolumn{1}{c|}{$\mathrm{R}^{2}$} & Nilai t \\
\hline Kandungan Gizi & 0.62 & 0.39 & 7.91 \\
\hline Tekstur & 0.65 & 0.42 & 8.32 \\
\hline Kelezatan & 0.68 & 0.47 & 8.93 \\
\hline Rasa & 0.95 & 0.89 & 14.37 \\
\hline Aroma & 0.69 & 0.47 & 9.00 \\
\hline Warna & 0.67 & 0.45 & 8.68 \\
\hline Bentuk & 0.65 & 0.42 & 8.32 \\
\hline
\end{tabular}

Berdasarkan tabel di atas dapat dijelaskan Nilai Loading untuk masing-masing indikator berada di atas 0.50 sehingga atribut-atribut diatas dapat di nyatakan sebagai atribut pembentuk variabel Atribut Intrinsik. Atribut Kandungan gizi memiliki loading sebesar 0.62 hal ini berarti atribut Kandungan gizi dapat di estimasi oleh atribut Atribut Intrinsik sebesar 0.62 dengan besar $\mathrm{R}^{2}$ (proporsi atribut kandungan gizi dapat dijelaskan oleh Atribut Intrinsik) sebesar 39\%. Atribut tekstur memiliki loading sebesar 0.65 hal ini berarti atribut tekstur dapat di estimasi oleh atribut Atribut Intrinsik sebesar 0.65 dengan besar $\mathrm{R}^{2}$ (proporsi atribut tekstur rasa dapat dijelaskan oleh Atribut Intrinsik) sebesar $42 \%$. Atribut kelezatan memiliki loading sebesar 0.68 hal ini berarti atribut kelezatan dapat di estimasi oleh atribut Atribut Intrinsik sebesar 0.68 dengan besar $\mathrm{R}^{2}$ (proporsi atribut kelezatan dapat dijelaskan oleh Atribut Intrinsik) sebesar 47\%. Atribut rasa memiliki loading sebesar 0.95 hal ini berarti atribut rasa dapat di estimasi oleh atribut Atribut Intrinsik sebesar 0.95 dengan besar $\mathrm{R}^{2}$ (proporsi atribut rasa dapat dijelaskan oleh Atribut Intrinsik) sebesar 89\%. Atribut aroma memiliki loading sebesar 0.69 hal ini berarti atribut aroma dapat di estimasi oleh atribut Atribut Intrinsik sebesar 0.69 dengan besar $\mathrm{R}^{2}$ (proporsi atribut aroma dapat dijelaskan oleh Atribut Intrinsik) sebesar $47 \%$. 
Atribut warna memiliki loading sebesar 0.67 hal ini berarti atribut warna dapat di estimasi oleh atribut Atribut Intrinsik sebesar 0.67 dengan besar $\mathrm{R}^{2}$ (proporsi atribut warna dapat dijelaskan oleh Atribut Intrinsik) sebesar 45\%. Atribut bentuk memiliki loading sebesar 0.67 hal ini berarti atribut bentuk dapat di estimasi oleh atribut Atribut Intrinsik sebesar 0.67 dengan besar $\mathrm{R}^{2}$ (proporsi atribut bentuk dapat dijelaskan oleh Atribut Intrinsik) sebesar $45 \%$.

\section{Atribut Atribut Ekstrinsik Merupakan Atribut yang Dipertimbangkan Konsumen Dalam Memilih Produk}

Adapun besarnya atribut Atribut ekstrinsik dapat di jelaskan oleh atribut Desain, Merek, Label, Harga, Polusi Terhadap Lingkungan, Bersih, dan Kemasan ditunjukkan pada tabel berikut.

Nilai Loading Atribut Variabek Atribut Produk Ekstrinsik

\begin{tabular}{|l|c|c|c|}
\hline \multicolumn{1}{|c|}{ Atribut } & Nilai Loading & \multicolumn{1}{c|}{$\mathrm{R}^{2}$} & Nilai t \\
\hline Desain & 0.67 & 0.45 & 8.67 \\
\hline Merek & 0.64 & 0.41 & 8.11 \\
\hline Label & 0.87 & 0.76 & 12.57 \\
\hline Harga & 0.87 & 0.76 & 12.62 \\
\hline $\begin{array}{l}\text { Polusi Terhadap } \\
\text { Lingkungan }\end{array}$ & 0.74 & 0.55 & 9.92 \\
\hline Kebersihan & 0.60 & 0.36 & 7.52 \\
\hline Kemasan & 0.62 & 0.39 & 7.83 \\
\hline
\end{tabular}

Berdasarkan tabel 5.14 di atas dapat dijelaskan Nilai Loading untuk masing-masing indikator berada di atas 0.50 sehingga atribut-atribut diatas dapat di nyatakan sebagai atribut pembentuk variabel Atribut Ekstrinsik. Atribut Desain memiliki loading sebesar 0.67 hal ini berarti atribut Desain dapat di estimasi oleh atribut Atribut Ekstrinsik sebesar 0.67 dengan besar $\mathrm{R}^{2}$ (proporsi atribut Desain dapat dijelaskan oleh Atribut Ekstrinsik) sebesar $45 \%$. Atribut Merek memiliki loading sebesar 0.64 hal ini berarti atribut Merek dapat di estimasi oleh atribut Atribut Ekstrinsik sebesar 0.64 dengan besar $\mathrm{R}^{2}$ (proporsi atribut Merek dapat dijelaskan oleh Atribut Ekstrinsik) sebesar 41\%. Atribut Label memiliki loading sebesar 0.87 hal ini berarti atribut Label dapat di estimasi oleh atribut Atribut Ekstrinsik sebesar 0.87 dengan besar $\mathrm{R}^{2}$ (proporsi atribut Label dapat dijelaskan oleh Atribut Ekstrinsik) sebesar 76\%. Atribut Harga memiliki loading sebesar 0.87 hal ini berarti atribut Harga dapat di estimasi oleh atribut Atribut Ekstrinsik sebesar 0.95 dengan besar $\mathrm{R}^{2}$ (proporsi atribut Harga dapat dijelaskan oleh Atribut Ekstrinsik) sebesar 89\%.

Dengan demikian dapat di berdasarkan hasil penelitian dapat disimpulkan bahwa atribut Desain, Merek, Label, Harga, Polusi Terhadap Lingkungan, Bersih, dan Kemasan merupakan atribut pembentuk atribut Atribut Produk Ekstrinsik, yang merupakan atribut yang dipertimbangkan konsumen dalam memilih produk. 


\section{Atribut Sensori (Aroma dan Rasa) Merupakan Atribut Produk yang Paling Dipertimbangkan Konsumen Dalam Memilih Produk Camilan Khas Malang.}

Berdasatkan hipotesis yang di ajukan atribut sensori (aroma dan rasa) merupakan atribut yang paling di pertimbangkan. Atribut produk yang paling di pertimbangkan konsumen dapat dilihat dari besarnya nilai atribut loading untuk masing-masing atribut . Nilai loading yang paling besar merupakan atribut yang paling di pertimbangkan konsumen dalam memilih produk camilan khas malang. Berdasarkan hasil penelitian atribut produk yang paling di pertimbangkan konsumen untuk atribut atribut intrinsik adalah atribut rasa dengan nilai loading 0.95 dan nilai $\mathrm{R}^{2}$ (proporsi atribut yang dapat dijelaskan oleh Atribut intrinsik) sebesar $89 \%$. Sedangkan untuk atribut ekstrinsik atribut yang paling di pertimbangkan adalah atribut label dan harga dengan masing-masing nilai loading sebesar 0.87 dan nilai $\mathrm{R}^{2}$ (proporsi atribut yang dapat dijelaskan oleh Atribut intrinsik) sebesar $76 \%$. Sehingga dalam penelitian ini hipotesis yang menyatakan bahwa atribut sensori (aroma dan rasa) merupakan atribut yang paling di pertimbangkan konsumen dalam memilih produk khas Malang di terima.

\section{PEMBAHASAN}

Dari hasil penelitian di atas dapat dilihat bahwa Kandungan Gizi merupakan salah satu pembentuk faktor Atribut Produk Intrinsik. Artinya bahwa dalam membeli sebuah produk makanan khas, konsumen sangat memperhatikan kandungan Gizi yang terkandung dalamnya, seperti kandungan vitamin dan mineral yang sering dipertimbangkan konsumen. Keyakinan konsumen terhadap kandungan gizi yang terkandung dalam produk camilan khas Malang cukup tinggi karena produk camilan ini menggunakan bahan-bahan yang alami dan sangat dikenal oleh konsumen, sehingga tingginya keyakinan konsumen terhadap kandungan gizi yang terkandung dalam camilan khas Malang menyebabkan atribut ini menjadi pertimbangan bagi konsumen dalam memilih camilan khas Malang. Diantara seluruh atribut yang membentuk atribut atribut intrinsik, atribut Kandungan Gizi memiliki nilai terendah dari seluruh atribut yang membentuk atribut atribut intrinsik. Artinya bahwa atribut Kandungan Gizi mampu menarik perhatian konsumen untuk membeli produk camilan khas Malang. Hal ini sejalan dengan pendapat Sanzo et al (dalam Carmina Fandos dan Carlos Flavian 2006:649) yang mengkatagorikan Kandungan Gizi (Vitamin dan Mineral) sebagai salah satu atribut dalam atribut produk Intrinsik. Tekstur dalam penelitian ini juga merupakan salah satu pembentuk atribut Atribut Produk Intrinsik. Artinya bahwa dalam membeli sebuah produk makanan khas, konsumen sangat memperhatikan tekstur sebuah produk, seperti tingkat kerenyahannya, kelembutannya maupun tingkat kepadatannya ketika sebuah camilan itu di konsumsi. Perhatian konsumen pada atribut ini cukup tinggi karena produk camilan khas Malang ini terbuat dari bahan-bahan sulit di terbentuk teksturnya, sehingga konsumen merasa penting untuk mempertimbangkan atribut ini dalam memilih produk camilan khas Malang.Hal ini sesuai dengan penelitian Carmina Fandos dan Carlos Flavian (2006:654) yang menganalisis atribut tekstur (special texture) sebagai atribut yang membentuk atribut produk intrinsik karena tekstur dapat di identifikasi ketika produk di konsumsi. Kelezatan dalam penelitian ini merupakan salah satu pembentuk faktor Atribut Produk Intrinsik. Artinya bahwa dalam memilih produk makanan khas, konsumen sangat memperhatikan kelezatan, kelezatan yang dirasakan konsumen ketika mengkonsumsi produk camilan khas Malang mampu menarik minat konsumen untuk membeli produk camilan khas Malang, karena atribut kelezatan berkaitan dengan bahan dasar produk camilan khas malang yang berasal dari bahan-bahan yang alami tetapi menggunakan proses pengolahan yang berbeda dan menghasilkan produk yang berbeda sehingga 
konsumen merasa penting untuk memperhatikan atribut kelezatan dalam memilih produk camilan khas Malang. Hal ini sesuai dengan pendapat Carmina Fandos dan Carlos Flavian (2006:654) yang menganalisis atribut bumbu yang di sukai sebagai pembentuk kelezatan suatu produk yang merupakan atribut pembentuk atribut produk intrisik. Aroma dalam penelitian ini merupakan salah satu pembentuk atribut Atribut Produk Intrinsik. Artinya bahwa dalam memilih produk makanan khas, konsumen sangat memperhatikan aroma yang di hasilkan oleh produk camilan khas Malang. Aroma yang di rasakan konsumen ketika mengkonsumsi produk camilan khas Malang mampu menarik minat konsumen untuk membeli produk camilan khas Malang, karena atribut aroma berkaitan dengan kesesuaian bau yang di hasilkan produk camilan khas Malang dengan bahan baku yang digunakan untuk memproduksi produk camilan khas Malang. Sehingga konsumen merasa lebih yakin bahwa produk tersebut menggunakan bahan baku yang alami karena menghasilkan aroma yang sesuai dengan bahan baku yang digunakan. Hal ini sesuai dengan pendapat Carmina Fandos dan Carlos Flavian (2006:654) yang menganalisis aroma yang di sukai sebagai (agreeable aroma) sebagai atribut yang membentuk atribut produk intrinsik karena aroma dapat di identifikasi ketika produkakan di konsumsi. Warna dalam penelitian ini merupakan salah satu pembentuk atribut Atribut Produk Intrinsik. Artinya bahwa dalam memilih produk makanan khas, konsumen sangat memperhatikan warna dari produk camilan khas Malang.Warna mampu menarik minat konsumen untuk membeli produk camilan khas Malang, karena atribut warna berkaitan dengan keaslian warna bahan baku produk sebelum diolah dan sesudah diolah. Sehingga konsumen merasa yakin bahwa produk ini merupakan produk asli yang mempunyai warna yang sesuai dengan bahan baku tetapi cara pengolahannya berbeda. Hal ini sesuai dengan pendapat Carmina Fandos dan Carlos Flavian (2006:654) yang menganalisis atribut warna yang bagus sebagai atribut pembentuk atribut produk intrisik. Bentuk dalam penelitian ini merupakan salah satu pembentuk atribut Atribut Produk Intrinsik. Artinya bahwa dalam memilih produk makanan khas, konsumen sangat memperhatikan bentuk produk camilan khas Malang. Bentuk yang terlihat konsumen ketika mengamati produk camilan khas Malang mampu menarik minat konsumen untuk membeli produk camilan khas Malang, karena atribut bentuk ini berkaitan dengan kesesuaian bentuk sebelum dan sesudah pengolahan. Sehingga produk olahan tersebut benar merupakan hasil olahan dari bahan alami dengan melihat bentuk produk yang tidak terlalu berbeda dengan bahan bakunya. Dari hasil penelitian diketahui bahwa Desain merupakan salah satu pembentuk faktor atribut produk ekstrinsik. Artinya bahwa dalam membeli sebuah produk makanan khas, konsumen sangat memperhatikan desain kemasan yang dapat terlihat ketika konsumen pertama kali melihat sebuah produk, seperti kombinasi warna, susunan gambar yang di tampilkan dan bentuk tulisan yang menampilkan kekhasan dan keaslian sebuah produk. Sehingga konsumen merasa yakin bahwa produk tersebut benar-benar produk khas Malang.Perhatian konsumen pada atribut ini cukup tinggi karena atribut ini akan terlihat pertama kali ketika konsumen melihat sebuah produk. Atribut desain merupakan merupakan salah satu pembentuk faktor atribut produk ekstrinsik, sesuai dengan pendapat Sanzo et al. (dalam Carmina Fandos dan Carlos Flavian 2006:649) yang menyatakan bahwa design merupakan salah satu fakor atribut produk ekstrinsik. Merek merupakan salah satu pembentuk atribut atribut produk ekstrinsik. Artinya bahwa dalam membeli sebuah produk makanan khas, konsumen sangat memperhatikan merek yang tercantum dalam kemasan, seperti nama, istilah, tanda, symbol yang menampilkan produk khas Malang. Merek mampu menarik minat konsumen karena atribut merek sangat berkaitan dengan kekhasan suatu daerah yang tidak dimiliki oleh daerah lain. Perhatian konsumen terhadap atribut ini cukup tinggi karena hal ini dapat meyakinkan konsumen bahwa produk yang di pilih benar-benar produk asli daerah Malang. Atribut merek merupakan 
salah satu pembentuk atribut atribut ekstrinsik, Label merupakan salah satu pembentuk faktor atribut produk ekstrinsik. Artinya bahwa dalam membeli sebuah produk makanan khas, konsumen sangat memperhatikan label yang tercantum dalam kemasan produk makanan khas, Label mampu menarik minat konsumen karena atribut label sangat berkaitan dengan informasi tentang jenis rasa, komposisi, dan label dinas kesehatan, label juga menampilkan perusahaan pembuat produk, tempat pembuatan, maupun cara penggunaan dan penyimpanan. Perhatian konsumen terhadap atribut ini cukup tinggi karena hal ini dapat memberikan jaminan kepada konsumen tentang kualitas dan keamanan produk khas Malang. Harga merupakan salah satu pembentuk atribut atribut produk ekstrinsik. Artinya bahwa dalam membeli sebuah produk makanan khas, konsumen sangat memperhatikan harga produk. Perhatian konsumen terhadap atribut ini cukup tinggi karena berhubungan dengan kemampuan konsumen dalam menjangkau harga yang di tawarkan. Polusi terhadap lingkungan merupakan salah satu pembentuk atribut atribut produk ekstrinsik. Artinya bahwa dalam membeli sebuah produk makanan khas, konsumen sangat memperhatikan tingkat polusi terhadap lingkungannya. Polusi terhadap lingkungan mampu menarik minat konsumen karena atribut Polusi terhadap lingkungan sangat berkaitan dengan kebersihan dan kesehatan lingkungan konsumen. Perhatian konsumen terhadap atribut ini cukup tinggi karena berhubungan dengan jumlah sampah dan tingkat bahayanya terhadap lingkungan Bersih merupakan salah satu pembentuk atribut atribut produk ekstrinsik. Artinya bahwa dalam membeli sebuah produk makanan khas, konsumen sangat memperhatikan kebersihan suatu produk. Baik dalam produk jadi maupun dalam proses pengolahannya. Atribut kebersihan mampu menarik minat konsumen karena atribut ini sangat berkaitan dengan jaminan kesehatan dan jaminan kualitas sebuah produk. Kemasan merupakan salah satu pembentuk faktor atribut produk ekstrinsik.Artinya bahwa dalam membeli sebuah produk makanan khas, konsumen sangat memperhatikan kemasan yang melindungi sebuah produk.Atribut kemasan ini dapat menarik minat konsumen karena hal ini dapat menjamin kualitas, kebersihan serta daya tahan sebuah produk, sehingga konsumen merasa kualitas produk dalam kemasan tidak akan berubah dalam jangka waktu tertentu sesuai dengan tanggal kadaluarsa yang telah di tentukan. Aroma dan Rasa merupakan salah satu atribut yang dipertimbangkan konsumen dalam memilih produk khas Malang yang termasuk kedalam salah satu atribut pembentuk variabel atribut produk intrinsik. Pada variabel atribut produk intrinsik atribut rasa, kelezatan dan aroma yang di tawarkan dapat mempengaruhi minat konsumen dalam memilih produk khas Malang. Atribut ini sangat dipertimbangkan konsumen karena konsumen dapat memilih sendiri rasa yang sesuai dengan selera. Sehingga produk khas malang ini dapat dinikmati oleh konsumen dari berbagai kalangan. Sedangkan pada faktor atribut produk ekstrinsik atribut yang di pertimbangkan konsumen yaitu atribut label dan harga karena label dapat memberikan informasi tentang pilihan rasa yang di inginkan konsumen, dan harga merupakan pertimabangan konsumen tentang kemampuannya membeli produk. Berdasarkan hasil distribusi juga dinyatakan bahwa label dan harga merupakan atribut yang penting bagi konsumen dalam memilih produk khas Malang.

\section{KESIMPULAN}

Atribut produk intrinsik terdiri dari: kandungan gizi, tekstur, kelezatan, rasa, aroma, warna dan bentuk merupakan atribut yang menjadi pertimbangan konsumen dalam memilih produk camilan khas Malang. Atribut produk ekstrinsik terdiri dari: desain, merek, label, harga, polusi terhadap lingkungan, bersih, dan kemasan merupakan atribut 
yang menjadi pertimbangan konsumen dalam memilih produk camilan khas Malang. Atribut sensori (aroma dan rasa) dalam atribut produk intrinsik merupakan atribut yang paling dipertimbangkan konsumen dalam memilih produk camilan khas Malang.

\section{DAFTAR PUSTAKA}

Alma, B. 2004.Manajemen Pemasaran dan Pemasaran Jasa. Bandung: Alfabeta.

Arikunto, Suharsimi. 2006. Prosedur Penelitian Suatu Pendekatan Praktik. Edisi Revisi VI. Jakarta: PT Rineka Cipta.

Azwar, Saifudin. 2003. Metode Penelitian. Yogyakarta: Pustaka Pelajar.

Cooper, Donald R., and Pamela, Schlinder. 2003. Business ResearchMethodes. North America: Seventh Edition, Mc Graw-HillInternational.

C.M. Lingga Purnama, MM. (2002). Strategic Marketing Plan. Jakarta: PT. Gramedia Pustaka

Espejel, et. al. 2007. The role of intrinsic and extrinsic quality attributes on consumer behaviour for traditional food products. Journal of Managing Service Quality. Vol. 17 No. 6, pp. 681-701

Fandos, Carmina \& Flavia'n, Carlos. 2006. Intrinsic and extrinsic quality attributes, loyalty and buying intention: an analysis for a PDO product. Journal of British Food Journal. Vol. 108 No. 8, pp. 646-662

Ferdinand, Agusty. 2006. Metode Penelitian Manajemen. Edisi 2. Semarang: Badan Penerbit Universitas Diponogoro.

Ferrinadewi, E \& Darmawan, D. 2004.Perilaku Konsumen: Analisis Model Keputusan. Yogyakarta: Universitas Atma Jaya Yogyakarta.

Ferrinadewi, Erna. 2005. Atribut Produk yang Dipertimbangkan dalam Pembelian Kosmetik dan Pengaruhnya pada Kepuasan Konsumen di Surabaya. Jurnal Manajemen \& Kewirausahaan, Vol. 7, No. 2, 139-151

Gitosudarmo, I. 2000. Manajemen Pemasaran. Yogyakarta: BPFE Yogyakarta.

Ghazali, Imam. 2005. Structural Equation Modeling: Teori,konsep dan Aplikasi dengan program Lisrel. Semarang: Badan Penerbit Universitas Diponogoro.

Ghazali, Imam. 2006. Aplikasi Analisis Multivariate Dengan Program SPSS. Semarang: Badan Penerbit Universitas Diponogoro.

Hadi, S. 2004. Metodologi Rasearch. Yogyakarta: Andi.

Kotler, P. 2000. Manajemen Pemasaran: Edisi Milenium. Jilid 1.Terjemehan Oleh Teguh dan Rony A. Rusli. 2002. Jakarta: PT Prenhalindo. 
Kotler, P. 2000. Manajemen Pemasaran: Edisi Milenium. Jilid 2.Terjemehan Oleh Teguh dan Rony A. Rusli. 2002. Jakarta: PT Prenhalindo.

Kotler.P. \& Armstrong, G. 2003.Prinsip-Prinsip Pemasarn Jilid 1. Jakarta: Erlangga.

Kerlinger, Fred N. Asas-asas Penelitian Behavorial. 2003. Yogyakarta: Gajahmada University Press.

Lupiyoadi, R. 2001. Manajemen Pemasaran Jasa: Teori dan Praktek 1. Jakarta: Salemba Empat.

Malhotra, Naresh K. Riset Pemasaran Pendekatan Terapan. Jilid 1. 2005. Klaten: PT.INDEKS

Masri Singarimbun dan Sofyan Effendi. 1995. Metode Penelitian Survai.Jakarta : LP3ES.

Moh. Nazir. 1988. Metode Penelitian. Jakarta: Cetakan ketiga, GhaliaIndonesia.

Porter, Michael E. 2007. Strategi Bersaing (competitive strategy). Terjemahan. Tangerang: Karisma Publishing Group.

Schiffan \& Kanuk. 2000. Consumer Behavior. New Jerssey: Prentice Hall

Sunarto. 2003. Perilaku Konsumen. Yogyakarta: AMUS Yogyakarta dan CV Ngeksigondo Multisarana Utama.

Sugiyono. 2004. Metode Peneltian Bisnis. Bandung: Alfabeta.

Sutisna. 2002. Perilaku Konsumen \& Komunikasi Pemasaran. Bandung: PT Remaja Rusdakarya.

Swastha, B. \& Irawan. 2001. Manajemen Pemasaran Modern. Yogyakarta: Liberty.

Tjiptono, F. 1998. Stategi Pemasaran. Yogyakarta: Andi Offset.

Widayat. 2004. Metode Penelitian Pemasaran: Aplikasi Software SPSS.Malang: UMM Pess.

Wood, Lisa. 2007. Functional and symbolic attributes of product selection. Journal of British Food Journal. Vol. 109 No. 2, pp. 108-118.

Zhang, Zhimin. 2002. Casual Wear Attributes: A Chinese Consumers' Perspective. Journal of Fashion marketing and management. Vol. 6 No. 1, pp. 53-62 